\title{
Análise de corpos hídricos constituintes do Riacho das Piabas em Campina Grande/PB
}

\author{
Analysis of water bodies constituents from the creek minnows in Campina Grande/ PB
}

\author{
Viviane Farias Silva', Aline Costa Ferreira², Vanessa Farias Silva ${ }^{3}$, Jose Geraldo Vasconcelos Baracuhy ${ }^{4}$ \\ 'Mestranda em Irrigação e Drenagem, Universidade Federal de Campina Grande-UFCG, Campina Grande, Paraíba, Brasil \\ 2 Doutora em Irrigação e Drenagem, Universidade Federal de Campina Grande-UFCG, Campina Grande, Paraíba, Brasil \\ ${ }^{3}$ Doutora em Química, Insa - Instituto Nacional do Semiárido, Campina Grande, Paraíba, Brasil \\ ${ }^{4}$ Professor, Universidade Federal de Campina Grande-UFCG, Campina Grande, Paraíba, Brasil
}

\begin{abstract}
Resumo
Os recursos naturais renováveis são considerados inexauríveis decorrentes a capacidade de restauração após uso pelo homem, quando utilizada de forma adequada. Nesse contexto, a presente pesquisa foi realizada na Microbacia hidrográfica do Riacho das Piabas objetivando-se avaliar a qualidade de água dos corpos hídricos constituintes do riacho das piabas para diversos fins. Foram coletadas 8 (oito) amostras de água em fontes naturais superficiais, como riachos, nascente e açudes; e fontes sub-superficiais, como poços e cacimbas e analisados o potencial hidrogeniônico $(\mathrm{pH})$, Condutividade elétrica (Ce), Turbidez e Oxigênio dissolvido (OD). O parâmetro Condutividade Elétrica da água de irrigação (CEa) possui grau de restrição de nenhuma (<0,70 dS m-1) a ligeira e moderada (0,70-3,00 dS m-1), com valor mínimo de 0,29 dS m-1 e máximo de 2,23 dS m-1. Na turbidez o maior valor encontrado foi de 1,9 NTU e o menor 1,3. Em todas as amostras os valores de oxigênio dissolvido são superiores a $5 \mathrm{mg} / \mathrm{L}$, recomendados pela Portaria MS 2914/2011. As amostras analisadas podem ser utilizadas para os animais, porém existe restrições em relação ao consumo humano e na irrigação.
\end{abstract}

Palavras-chaves: Qualidade de água, potabilidade, fontes superficiais.

\begin{abstract}
Renewable natural resources are considered inexhaustible arising from to capacity for restoration after use by man, when used appropriately. In this context, this research was carried out in the catchment of the creek Piabas aiming to assess the water quality constituents of water bodies from the creek minnows for various purposes. Eight (8) water samples were collected in shallow natural sources such as streams , ponds and spring; and sub - surface sources such as wells and ponds and analyzed the hydrogen potential ( $\mathrm{pH}$ ), electrical conductivity (EC), turbidity and dissolved oxygen ( DO). The Electrical Conductivity parameter of irrigation water ( EC w ) has no degree of restriction $(<0.70 \mathrm{dS} \mathrm{m}-1)$ mild and moderate ( 0.70 to $3.00 \mathrm{dS} \mathrm{m}-1)$, with a minimum value of $029 \mathrm{dS} \mathrm{m}-1$ and a maximum of $2.23 \mathrm{dS} \mathrm{m}-1$. Turbidity in the highest value was 1.9 and the lowest $1.3 \mathrm{NTU}$. In all samples the dissolved oxygen values are greater than $5 \mathrm{mg} / \mathrm{L}$ recommended by the MS 2914/2011. As samples can be used for animals, but there restrictions with regard for human consumption and irrigation .
\end{abstract}

Keywords: Water quality, potability, surface sources. 


\section{INTRODUÇÃO}

A água é um recurso natural com grande importância para a existência de vida na Terra. É a substância mais abundante no corpo humano, representando cerca de 60 a 70\% de seu peso (JACOB, 1990). Os recursos naturais renováveis são considerados inexauríveis quando utilizada de forma correta e com capacidade de restauração após uso pelo homem. Atualmente devido o seu inadequado uso pode-se tornar um recurso escasso por ter sua capacidade de renovação afetada pelas ações antrópicas.

Caubet (2006) afirma que dois milhões de seres humanos, principalmente crianças, morrem anualmente, nos países mais pobres, por causa de doenças gastrintestinais, propagadas pela falta de água tratada. Segundo a Organização Mundial de Saúde, no Brasil, "morrem atualmente 29 pessoas ao dia por doenças decorrentes da qualidade da água e do não tratamento de esgotos e estima-se que cerca de $70 \%$ dos leitos dos hospitais estejam ocupados por pessoas que contraíram doenças transmitidas pela água" (JÚNIOR, 2013).

A água destinada ao consumo humano, segundo Amaral et al., (2003) é um dos importantes veículos de enfermidades diarreicas de natureza infecciosa, o que torna primordial a avaliação de sua qualidade microbiológica. Segundo Carvalho (2007), a água tratada é a melhor forma de reduzir a mortalidade relacionada ao consumo de água contaminada.

Lima e Chaves (2008), afirma que a qualidade da água refere-se a sua adaptabilidade para determinado uso, isto é de suas características físicas, químicas e microbiológicas são adequadas às necessidades do usuário, e de um modo geral depende das condições geológicas, geomorfológicas e de cobertura vegetal da bacia de drenagem, do comportamento dos ecossistemas terrestres e de água doces e das ações do homem, dentre as quais se destaca o lançamento de cargas nos sistemas hídricos; a alteração do uso do solo rural, urbano e modificações no sistema hídrico.

Dispor de uma água de qualidade é condição indispensável para a manutenção da vida, visto que a qualidade da água consumida influencia diretamente na saúde das pessoas (ANTUNES e FREO, 2008).

Silva et al., (2013) relata sobre a importância de analisar as fontes hídricas para os diferentes tipos de uso que requerem padrões de qualidade da água adequados para cada atividade. Entretanto, a qualidade da água tem que ser entendida como um padrão relativo, ou seja, de acordo com cada utilização da água as requisições físico-químicas são diferentes. Dessa forma, há legislações especificas que estabelecem os limites dos parâmetros permitidos e adequados para os diversos usos da água. Os resultados das analises físico-químicas servem como índices para avaliar o dano deste uso da água sobre o ambiente aquático e subsidiar ações de gestão dos recursos hídricos e mitigação de impactos ambientais.

Nesse contexto, a presente pesquisa foi realizada objetivando-se avaliar a qualidade de água dos corpos hídricos constituintes do riacho das piabas para diversos fins.

\section{MATERIAL E MÉTODOS}

O município de Campina Grande encontra-se inserido nos domínios da bacia hidrográfica do Rio Paraíba, região do Médio Paraíba. Os principais cursos d'água são: os rios Salgadinho, Bodocongó, São Pedro, do Cruzeiro e Surrão, além dos riachos: Logradouro, das Piabas, Marinho, Caieira, do Tronco e Cunha. Os principais corpos de acumulação são os açudes: São Pedro, da Fazenda Quilombo e Campo de Bó. Os principais cursos d' água têm regime de escoamento intermitente e o padrão de drenagem é o dendrítico (BRASIL, 2001).

A área da pesquisa pertence à Microbacia hidrográfica do Riacho das Piabas, localiza-se entre as latitudes sul $7^{\circ} 12^{\prime} 18$ “e $7^{\circ} 09^{\prime} 28^{\prime}$ " e longitude oeste de $35^{\circ} 52^{\prime} 50$ "e $35^{\circ} 55^{\prime}$ ' $02^{\prime}$ ”, com altitude máxima de $688,85 \mathrm{~m}$ a montante e mínima de $536,14 \mathrm{~m}$ a jusante. Pertencendo naturalmente a região do médio curso da Bacia Hidrográfica do Rio Paraíba tem suas nascentes localizadas próximo às divisas dos municípios de Lagoa Seca e Campina Grande-PB (Figura 1). Porém é atualmente enquadrada como região do baixo curso da Bacia Hidrográfica do Rio Paraíba através de obra de desvio de águas pluviais na cidade de Campina Grande. 
Foram coletadas 8 (oito) amostras de água em fontes naturais superficiais, como riachos, nascente e açudes; e fontes sub-superficiais, como poços e cacimbas (Figura 01).

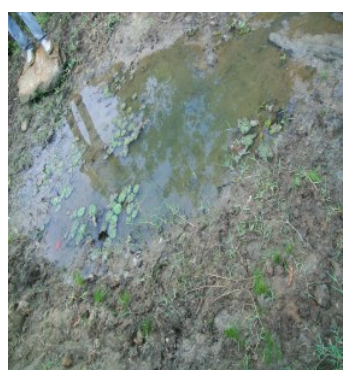

Amostra 1

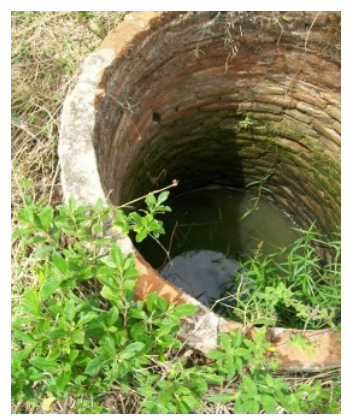

Amostra 5

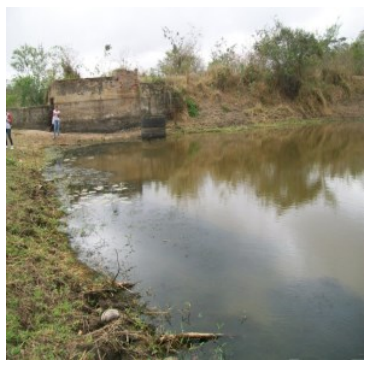

Amostra 2

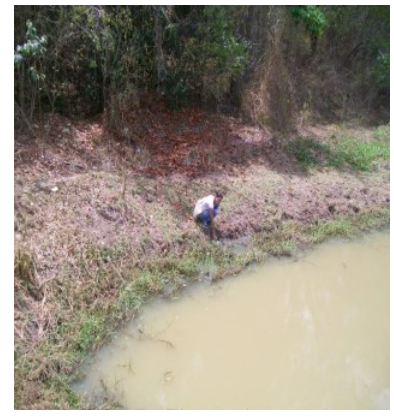

Amostra 6

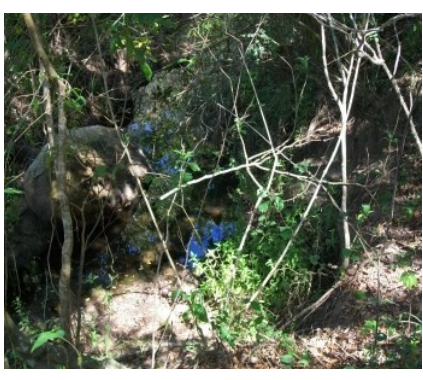

Amostra 3

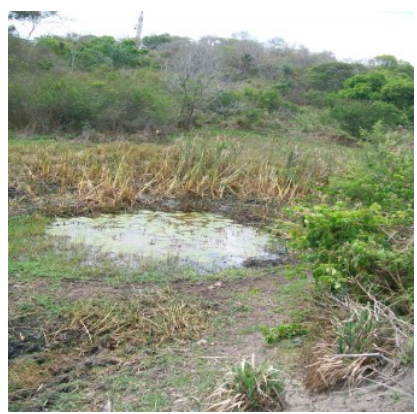

Amostra 7

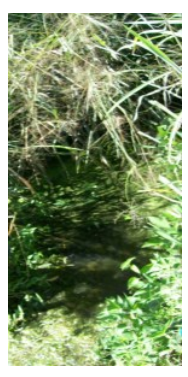

Amostra 4

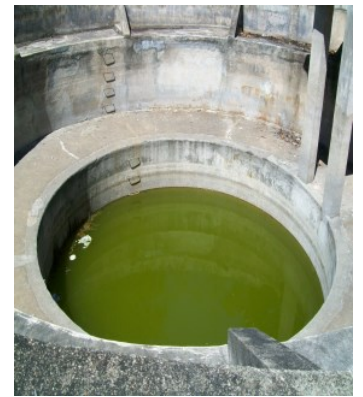

Amostra 8

Figura 01- imagens dos locais onde foram coletadas as amostras.

Fonte: Fotografia tirada pela autora

Todos os pontos de coleta de amostra foram georreferenciados com o auxilio do Global Positioning System (GPS) além da realização de imagens do local com maquina fotográfica. Depois de armazenada em garrafas PET as amostras foram analisadas de acordo com suas características físico-químicas. Os parâmetros analisados foram: potencial hidrogeniônico $(\mathrm{pH})$, Condutividade $(\mathrm{Ce})$, Turbidez e Oxigênio dissolvido (OD).

Para o enquadramento da água para consumo humano foi utilizada a Portaria $n^{\circ} 2914$ do Ministério da Saúde de 12/12/2011 para determinar e classificar os padrões de potabilidade da água, de um modo geral, são valores máximos permitidos (VMP) de concentração para uma série de substâncias e componentes presentes na água.

Em relação às analises dos parâmetros referente à utilização da água da bacia hidrográfica do Riacho das Piabas para fins de irrigação, foram utilizadas as referências citadas por Ayres e Westcot(1999) conforme UCCC(1974) para irrigação com os parâmetros de pH e CEa, e conforme Academia Nacional de Ciências dos EUA (1972) utilizando o parâmetro de CEa como meio de avaliar a restrição do seu uso para fins de dessedentação animal.

\section{RESULTADOS E DISCUSSÕES}

As determinações físico-química analisadas apresentados na Tabela 01, indicam que o parâmetro Condutividade Elétrica da água de irrigação (CEa) possui grau de restrição de nenhuma $(<0,70$ dS m-1) a ligeira e moderada (0,70-3,00 dS m-1), com valor mínimo de 0,29 dS m-1 e máximo de 2,23 dS m-1. Apenas a amostra 1 é considerada de severo grau de restrição de uso para a irrigação com 4,41 dSm-1,portanto, a utilização dessa água para fins agrícolas faz-se necessário a adoção de medidas de manejo tais como adição de matéria orgânica, gradagem etc., caso contrário, a redução da taxa de infiltração de água no solo pode ser intensificada. 
Tabela 01- Parâmetros físico-químicos avaliados: $\mathrm{pH}$, condutividade elétrica, turbidez e oxigênio dissolvido do Riacho das Piabas-PB e avaliação de estatística descritiva.

\begin{tabular}{cccccc}
\hline Amostras & $\mathbf{p H}$ & $\mathbf{C E a}\left(\mathbf{d S m}^{-1}\right)$ & Turbidez(NTU) & OD $\left(\mathbf{m g ~ L}^{-1}\right)$ \\
\hline 1 & 6,44 & 4,41 & 1,9 & 5,63 \\
2 & 5,86 & 2,15 & 1,6 & 12,60 \\
3 & 6,13 & 1,97 & 1,4 & 10,28 \\
4 & 5,65 & 0,43 & 1,3 & 5,24 \\
5 & 5,33 & 2,22 & 1,4 & 21,90 \\
6 & 5,31 & 1,05 & 1,3 & 110,03 \\
7 & 5,77 & 2,23 & 1,3 & 30,61 \\
8 & 6,01 & 0,29 & 1,4 & 12,60 \\
Média & & 1,84 & 1,45 & 26,11 \\
Máximo & 6,44 & 4,41 & 1,90 & 110,03 \\
Mínimo & 5,31 & 0,29 & 1,30 & 5,24 \\
Desv.padrao & & 1,23 & 0,19 & 32,69 \\
CV\% & & 66,51 & 13,36 & 125,21 \\
\hline
\end{tabular}

Para as águas com a restrição ligeira e moderada ao uso na irrigação exige cuidado gradual na seleção das culturas e das alternativas de manejo, de modo a se alcançar o potencial máximo de rendimento das culturas. Segundo Ayers e Westcot (1999) as águas com valores correspondentes a grau de restrição nenhuma ao uso na irrigação não apresentam problemas para a maioria das culturas e solos.

Conforme Ayers e Westcot (1999) os níveis de salinidade abaixo de 1,5 dSm-1 é excelente para todas as classes de gado e aves confinadas. E os níveis de salinidade entre 1,5 a $5 \mathrm{dSm}-1$ é satisfatória sendo adequada para todas as classes de gado e aves confinadas mas pode provocar diarreia temporária em gado não acostumado e excrementos aquosos nas aves. Por isso é indicado à compra de animais da própria região por já está adaptado à qualidade de água.

Percebe-se uma grande diferença no coeficiente de variação das amostras onde a menor apresenta $13,36 \%$ de variação enquanto a maior apresenta $125,21 \%$, visto que são fontes hídricas de uma mesma área e mostram uma grande variação nos resultados dos parâmetros analisados.

A influência do $\mathrm{pH}$ sobre os ecossistemas aquáticos naturais dá-se diretamente devido a seus efeitos sobre a fisiologia das diversas espécies. Também o efeito indireto é muito importante podendo, determinadas condições de $\mathrm{pH}$ contribuírem para a precipitação de elementos químicos tóxicos como metais pesados; outras condições podem exercer efeitos sobre as solubilidades de nutrientes (CETESB, 2004). Os valores de $\mathrm{pH}$ obtidos das amostras coletada foram de 5,31 a menor e a maior 6,44 (Tabela 01). Segundo Ayres e Westcot (1991) a faixa normal de $\mathrm{pH}$ da água para irrigação é de 6,5 a 8,4, ou seja, nenhuma amostra se encaixa na faixa normal, podendo essa acidez provocar desequilíbrio nutricionais para culturas e corrosão de equipamentos de irrigação.

Em cinco amostras o pH está alterado (Tabela 01), sendo mais baixo que o limite permitido. Quando ocorre a alteração do $\mathrm{pH}$ pode indicar a presença de agrotóxicos(SANTOS e WILSON,2008).

Coswosk et al., (2013) em estudo da potabilidade da água para consumo humano na cidade de colorado do oeste verificaram em suas amostras coletadas o $\mathrm{pH} 7$, o nível do $\mathrm{pH}$ é aceitável já que 
o valor esta dentro dos limites permitidos que é de $(6-9,5)$. Resultados contrários aos obtidos nesta pesquisa.

A Portaria $\mathrm{n}^{\circ} 2914 / 2011$ do Ministério da Saúde que dispõe sobre os procedimentos de controle e de vigilância da qualidade da água para consumo humano e seu padrão de potabilidade, recomenda que o $\mathrm{pH}$ aceitável da água esteja na faixa de 6,0 a 9,5, portanto o $\mathrm{pH}$ de apenas 3 fontes analisadas está em conformidade com a legislação, enquanto as demais não se enquadram.

A turbidez da água é um parâmetro influenciado pela presença de materiais sólidos em suspensão, que reduzem a sua transparência. Essa transparência pode ser alterada pela presença de algas, plâncton, matéria orgânica e muitas outras substâncias como o zinco, ferro, manganês e areia, resultantes do processo natural de erosão ou de despejos domésticos e industriais. Através das análises observa-se que todas as amostras estão dentro dos padrões de potabilidade do Ministério da Saúde, onde o Valor Maximo Permitido para qualquer amostra pontual (5 NTU) da turbidez. Logo o maior valor encontrado foi de 1,9 NTU e o menor 1,3, pois no momento da coleta percebeu-se que possuíam poucos sólidos em suspensão além da cor ser bastante clara.

O oxigênio dissolvido não é apenas essencial para os organismos aeróbios, mas também o principal parâmetro de caracterização dos efeitos da poluição das águas por despejos orgânicos. Durante a estabilização da matéria orgânica as bactérias utilizam oxigênio em seus processos respiratórios, podendo reduzir sua concentração nos esgotos tratados ou em cursos d'água (VON SPERLING, 2005).

Águas poluídas são aquelas que apresentam baixa concentração de oxigênio dissolvido (devido ao seu consumo na decomposição de compostos orgânicos), enquanto que as águas limpas apresentam concentrações de oxigênio dissolvido elevadas, chegando até a um pouco abaixo da concentração de saturação. No entanto, uma água eutrofizada pode apresentar concentrações de oxigênio bem superiores a $10 \mathrm{mg} / \mathrm{L}$, mesmo em temperaturas superiores a $20^{\circ} \mathrm{C}$, caracterizando uma situação de supersaturação. Isto ocorre principalmente em lagos de baixa velocidade aonde chegam a se formar crostas verdes de algas à superfície (CETESB, 2008). O que explicaria os valores maiores de $10 \mathrm{mg} / \mathrm{L}$ de oxigênio dissolvido de algumas amostras coletadas.

Nas águas naturais, o oxigênio é indispensável também para outros seres vivos, especialmente os peixes, onde a maioria das espécies não resiste a concentrações de oxigênio dissolvido na água inferiores a 4,0 mg/L(PINTO et al.,2010). De acordo com a Resolução Conama 357/2005 (BRASIL, 2005a), regulamentada pela Portaria MS 2914/2011, o limite mínimo para oxigênio dissolvido é 4 $\mathrm{mg} / \mathrm{L}$. Logo em todas as amostras os valores são superiores a $5 \mathrm{mg} / \mathrm{L}$ de oxigênio dissolvido.

Segundo Santos e Wilson (2008) o Valor Máximo Permitido pela Portaria do Ministério da Saúde (MS) 518/2004 (revogada pela Portaria n 2914/2011 do MS) de oxigênio dissolvido é de 100 $\mathrm{mg} / \mathrm{L}$, onde apenas uma amostra apresentou valor superior de $110,03 \mathrm{mg} / \mathrm{L}$ de oxigênio dissolvido.

Além de algumas alterações presentes nas análises como os parâmetros de oxigênio dissolvido e pH que estão na Tabela 01 podem também significar, de acordo com a Portaria 518/04 (revogada pela 2914/2011) "[...]. 1) potencial tóxico das substâncias químicas que podem estar presentes na água (naturalmente ou por contaminação); 2) análises das evidências epidemiológicas e toxicológicas dos riscos de saúde associadas às diversas substâncias; 3) possibilidades analíticas de determinação das substâncias em amostras de água; 4) intensidade de uso das substâncias químicas no País - uso industrial, agrícola e no tratamento da água". (BRASIL, 2005b). Tudo isso indica que as amostras de água não estão adequadas para o uso humano de acordo com os parâmetros estudados.

Segundo Sousa et al.(2008), existe uma intensa exploração de pequenas hortas nas proximidades das nascentes do Riacho das Piabas promove a destruição de ambientes frágeis e perda da biodiversidade, essa prática associada à aplicação de agrotóxicos constatada in loco em virtude das pragas das culturas exploradas maximiza o comprometimento da integridade ecológica da área inclusive provocando contaminação do ambiente aquático.

Por diversos fatores a qualidade da água é vulnerável, principalmente, devido às condições ambientais a qual está exposta. Preservar a qualidade da água é uma necessidade e ao mesmo tempo um problema universal, que vem exigindo o empenho não somente dos organismos de governo, mas também da sociedade civil organizada (SANTOS et al., 2013) . 


\section{CONCLUSÃO}

As águas analisadas podem ser utilizadas para dessedentação de gado e aves confinadas. Mas nenhuma foi considerada adequada para consumo humano, de acordo com os parâmetros analisados.

Para uso na irrigação as águas analisadas devem ser usadas com devido cuidado fazendo-se um monitoramento periódico para não ocorrer salinização do solo, lixiviação de nutrientes como também não corroer os equipamentos de irrigação.

\section{REFERÊNCIAS}

AMARAL, L. A. et a. Água de consumo humano como fator de risco à saúde em propriedades rurais. Rev Saúde Pública, v. 37, n. 4, p. 510-514, 2003.

ANTUNES, K. S. C.; FREO, J. D. Qualidade microbiológica da água de poços rasos e profundos localizados no município de Jaboticaba, RS. Revista Higiene Alimentar, São Paulo, v. 22, n. 159, p. 36-41, mar. 2008.

AYERS, R.S; WESTCOT, D. W. A qualidade da água na agricultura. "Water Quality for Agriculture". FAO. Tradução Gheyi. H. R. \& Medeiros, J.F de, UFPB.Campina Grande- PB, 217p. 1991.

AYERS, R.S; WESTCOT, D. W. A qualidade da água na agricultura. Estudos, irrigação e drenagem, 29. Revisado $1^{\circ} 2^{\circ}$ edição. Tradução Gheyi. H. R. \& Medeiros, J.F de, UFPB.Campina Grande- PB, 153p. 1999.

BRASIL. Ministério da Saúde. Comentários sobre a portaria No 518/2004. Brasília: Editora do Ministério da Saúde, 2005b.

BRASIL. Ministério das Minas e Energia. Secretaria de Minas e Metalurgia; CPRM - Serviço Geológico do Brasil [CD ROM] Geologia, tectônica e recursos minerais do Brasil, Sistema de Informações Geográficas SIG. Mapas na escala 1:2.500.000. Brasília: CPRM, 2001. Disponível em 04 CD's. Consulta: 20/05/2008.

BRASIL. Ministério do Meio Ambiente, Conselho Nacional do Meio Ambiente- CONAMA (2005), Resolução n.357, de 17 de março de 2005a. Dispõe sobre a classificação dos corpos de água e diretrizes ambientais para o seu enquadramento, bem como estabelece as condições e padrões de lançamento de efluentes, e dá outras providências. Diário Oficial da República Federativa do Brasil, Poder Executivo, Brasília, DF, 18 mar.2005c. Seção 1, p.58-63.

CARVALHO, J. dos P. Uso da fita teste H2S para análise Bacteriológica da água consumida pela população do Bairro Ronaldo Aragão, Zona leste de Porto Velho - RO. Porto Velho, 2007.

CAUBET, C. G. A Água, a lei, a política. Ministério do Meio Ambiente. Curitiba: Juruá, 2006.

CETESB. Companhia de Tecnologia de Saneamento Ambiental. Relatório de qualidade das águas interiores do Estado de São Paulo 2003. São Paulo: CETESB, 2004. 273p.

CETESB. Companhia de Tecnologia de Saneamento Básico. Significado Ambiental e Sanitário das Variáveis de Qualidade das Águas e dos Sedimentos e Metodologias Analíticas de Amostragem. São Paulo,2008:41 p.(série relatórios).

COSWOSK, R. C.; GEMELI, M. B.; OLIVEIRA, L. C. J.; FRAGA, C. I. M.; PAULA, N. R. F. Estudo da potabilidade da água para consumo humano na cidade de Colorado do Oeste. Revista Brasileira de Ciências da Amazônia, v2, n1 - 2013.

JACOB, S W; FRANCONE, C. A.; LOSSOW, W. J. Anatomia e Fisiologia Humana. 5. ed. Rio de Janeiro: Guanabara. Koogan, 1990. 
JÚNIOR, A. O. Consciência sobre a Água.2007 Disponível em: <http://www.uniagua.org.br/public_html/ website/default.asp?tp=3\&pag=trabalhos.htm \# consciencia >. Acesso 26 Ago 2013.

LIMA, V. L. de A.; CHAVES, L. H. G. Qualidade da água. Campina Grande: Agenda. 120 p. 2008.

LINSLEY, R.K..; FRANZINI, J.B. Engenharia de recurso hídricos. Mc Graw-Hill do Brasil, 1978, 798p.

PINTO,A.L.; OLIVEIRA, G. H.; PEREIRA, G. A. Avaliação da Eficiência da Utilização do Oxigênio Dissolvido como Principal Indicador da Qualidade das Águas superficiais da Bacia do Córrego Bom Jardim, Brasilândia/MS. Revista GEOMAE- Campo Mourão/PR. ISSN 2178-3306, V.1 n.1, p.69-82, $1^{\circ}$ semestre de 2010.

SANTOS, C.M.;WILSON,E.M.H. Qualidade da água para consumo humano no município de honório serpa: ênfase ao uso dos agrotóxicos. 2008. Disponível em < http://www.bvsde.paho.org/bvstox/fulltext/qualidade. pdf $>$ Acesso em: 15 de janeiro de 2013.

SANTOS, J. O.; SANTOS, R. M. S.; GOMES, M. A. D.; MIRANDA, R. C.; NOBREGA, I. G. M. Qualidade da água para consumo humano: Uma discussão necessária. Revista Brasileira de Gestão Ambiental- GVAA. V. 7, n. 2, p. 19-26, abr-jun, 2013.

SILVA, V. F.; BRITO, K. S. A. ; PEREIRA, J. S.; FERREIRA, A. C. Qualidade de água de fontes hídricas do rio Paraíba. $7^{\circ}$ Encontro Internacional das Águas. Recife-PE, FASA 2013.

SOUSA, V. G. Diagnóstico e prognóstico socioeconômico e ambiental das nascentes do Riacho das Piabas (PB). Campina Grande, 2010. 125 pg.

SOUSA,V.G.;TROVÃO,D.M.B.M.;FARIAS,S.A.D.;PEREIRA,J.P.G.;SILVA,S.S.F. Análise ambiental da microbacia hidrográfica do riacho das piabas, no trecho que compõe suas nascentes e a reserva urbana do louzeiro, campina grande - pb, através de imagens de satélite. QUALIT@S Revista Eletrônica.ISSN 1677-4280 V7.n.1. Ano 2008.

VON SPERLING, M. Introdução à qualidade das águas e ao tratamento de esgotos. Belo Horizonte: Departamento de Engenharia Sanitária e Ambiental. Belo Horizonte: Ed. da UFMG, 2005.

UCCC-University of California Committee of Consultants. Guidelines for interpretation of water quality for agriculture. Davis: University of California, 1974. 13p. Documento. 